\title{
ANALISIS NILAI TAMBAH DAN PENDAPATAN USAHA PRODUK OLAHAN KERUPUK WORTEL DAN SIRUP WORTEL (Daucus carota L) (Kasus di KWT Citeko Asri Desa Citeko Kecamatan Cisarua Kabupaten Bogor Provinsi Jawa Barat)
}

\author{
S. Wibowo ${ }^{1}$, A. Arysad $^{1 \mathrm{a}}$, A. Yusdiarti ${ }^{1}$ \\ ${ }^{1}$ Jurusan Agribisnis, Fakultas Pertanian, Universitas Djuanda Bogor \\ Jalan Tol Ciawi No. 1 Kotak Pos 35 Bogor 16720 \\ ${ }^{a}$ Korespondensi: Apendi Arsyad, Telp: 08129347542 Email: apendi.arsyad@unida.ac.id
}

\begin{abstract}
The research was conducted in KWT Citeko Asri Cisarua district Citeko village. The aim of the research to analyze the added value of processing and analyzing revenues carrots. Results of the analysis show the amount of value added value added carrot crackers Rp. 14,000 / kg with a percentage of $70 \%$ and carrot syrup obtained Rp. 3,500 / liter with a percentage of $46.67 \%$. Advantages of processed carrots crackers Rp 8444 / kg with a percentage of $60.32 \%$ while the carrot syrup profit of Rp 2,389 / liter with a percentage of $68.25 \%$, the added value of processed above shows that the value of high-value ratios as percentage $>40 \%$. revenue of $\mathrm{Rp} 2,446,725$, per month. Based on the business value of BEP cracker products as many as $136.6 \mathrm{~kg}$ of carrots or equal to USD 30357 , - per $\mathrm{kg}$ while the BEP as much as 133.0 liters of carrot syrup or equal to USD 11085 , - per liter. R / C of refined products of carrots crackers and carrot syrup that is equal to 1.33. Expected products processed from KWT Citeko Asri can be packaged with a better and more attractive so that people know the product more easily processed crackers carrots and carrot syrup.
\end{abstract}

Key words : Value added, Income, BEP and R/C

\begin{abstract}
ABSTRAK
Penelitian dilakukan di KWT Citeko Asri Desa Citeko Kecamatan Cisarua. Penelitian bertujuan untuk menganalisis nilai tambah dan menganalisis pendapatan usaha pengolahan wortel. Hasil analisis nilai tambah menunjukan besarnya nilai tambah kerupuk wortel sebesar Rp. 14.000/kg dengan persentase sebesar 70\% dan sirup wortel diperoleh sebesar Rp. 3.500/liter dengan persentase sebesar 46,67\%. Keuntungan dari olahan kerupuk wortel sebesar Rp 8.444/kg dengan persentase sebesar 60,32\% sedangkan keuntungan sirup wortel sebesar Rp 2.389/liter dengan persentase sebesar $68,25 \%$, nilai tambah dari olahan diatas menunjukan bahwa nilai rasio bernilai tinggi karena memiliki persentase $>40 \%$. pendapatan sebesar Rp 2.446.725,- per bulan. Berdasarkan dari nilai BEP usaha produk kerupuk wortel yaitu sebanyak 136,6 kg atau sama dengan Rp 30.357,- per kg sedangkan pada BEP sirup wortel sebanyak 133,0 liter atau sama dengan Rp 11.085,- per liter. R/C dari produk olahan kerupuk wortel dan sirup wortel yaitu sebesar 1,33. Diharapkan produk olahan dari KWT Citeko Asri dapat dikemas dengan baik dan lebih menarik sehingga masyarakat lebih mudah mengenal produk olahan kerupuk wortel dan sirup wortel.
\end{abstract}

Kata kunci : Nilai tambah, Pendapatan, BEP dan R/C Rasio 


\section{PENDAHULUAN}

Wortel sebagai salah satu komoditas hortikultura, sayuran mempunyai nilai komersial yang cukup tinggi, karena sayuran merupakan produk pertanian yang dikonsumsi setiap saat. Kebutuhan pasar akan sayuran terus mengalami peningkatan dengan adanya kecenderungan masyarakat untuk menerapkan pola hidup sehat dengan mengurangi konsumsi makanan berlemak tinggi dari bahan hewani ke bahan nabati. Tingginya permintaan terhadap sayuran juga dipengaruhi oleh meningkatnya jumlah penduduk, meningkatnya kesadaran gizi sejalan dengan peningkatan pendidikan dan kesejahteraan masyarakat, meningkatnya industri pengolahan dan industri pariwisata dan restoran, hotel serta pasar yang menginginkan jenis sayuran yang lebih beragam dengan mutu yang baik.

Konsumsi wortel untuk wilayah Jawa Barat dari data yang diperoleh pada tahun 2007 sebesar 1,147 (kg/kapita/tahun), pada tahun 2008 konsumsi wortel masih berada dalam kondisi yang sama yaitu sebesar 1,147 (kg/kapita/tahun), untuk kosumsi tahun 2009 mengalami penurunan menjadi 0,991 (kg/kapita/tahun). Pada tahun 2010 juga mengalami penurunan kembali menjadi 0,939 (kg/kapita/tahun) sedangkan pada tahun 2011 konsumsi wortel meningkat kembali menjadi 1,043 (kg/kapita/tahun) dan data yang diperoleh dalam rata-rata pertumbuhan konsumsi wortel dari tahun 2007-2011 sebesar -1,95 \% (Statistik Konsumsi Pangan, 2012).

Komoditi wortel ini tidak hanya dijual dalam bentuk segar, tetapi juga dalam bentuk olahan, dalam pembuatan olahan kerupuk dan sirup wortel untuk mendapatkan bahan baku sangat mudah dengan harga yang relatif murah. Sedangkan limbah dari sortiran dari lahan dapat dimanfaatkan menjadi olahan sehingga wortel tidak ada yang terbuang sia-sia. Daerah Desa Citeko petani membuat kelompok tani untuk membantu para petani dalam bercocok tanam wortel dan mendapatkan bantuan dari pemerintah baik dalam penyuluhan ataupun permodalan sehingga para petani membuat kelompok tani Bunga wortel. Kelompok tani bunga wortel mendirikan KWT Citeko Asri bertujuan untuk memanfaatkan waktu luang ibu rumah tangga dan wortel hasil pemanenan, sehingga diharapkan dari olahan wortel ini dapat membantu perekonomian keluarga petani. Wortel yang diolah oleh KWT Citeko Asri menjadi olahan seperti kerupuk wortel dan sirup wortel.

Pada saat harga wortel rendah yaitu sekitar Rp 500,- sampai Rp 2.000,- maka kegiatan pengolahan produk olahan wortel tersebut akan lebih baik atau memiliki nilai lebih ketika dilakukan oleh KWT Citeko Asri. Hal ini akan memperoleh pendapatan yang lebih tinggi dibandingkan dengan menjual wortel dalam bentuk segar.

Harga kerupuk wortel sebesar $\mathrm{Rp}$ 40.000 per $\mathrm{kg}$ sedangkan harga sirup wortel perliter sebesar Rp 15.000 per liter dari beberapa informasi di atas maka peneliti berkeinginan untuk meneliti kedua olahan tersebut. Dalam hal ini usaha yang dijalankan oleh KWT Citeko Asri sebagai usaha sampingan untuk membantu perekonomian rumah tangga petani dan memanfaatkan hasil pertanian yang diolah menjadi beberapa produk olahan seperti kerupuk wortel, sirup wortel dan lain-lain.

Mengingat produk olahan wortel di KWT Citeko Asri hanya dipasarkan sesuai permintaan konsumen maupun dipasarkan saat diadakannya pameran hasil pertanian dan permintaan dari olahan kerupuk wortel dan sirup wortel di beberapa warung yang 
berada di Desa Citeko . Pemasaran produk olahan berupa kerupuk wortel dan sirup wortel ini berkelanjutan sehingga dibutuhkan modal yang cukup besar pada pemasaran produk olahan kerupuk wortel dan sirup wortel. Oleh Kerena itu, dibuatlah analisis pendapatan untuk melihat apakah produk ini dapat memberikan penerimaan (income) bagi keluarga petani.

Berdasarkan latar belakang dan permasalahan yang telah dikemukakan sebelumnya, maka dapat dirumuskan beberapa permasalahan-permasalahan yaitu Berapakah nilai tambah wortel setelah diolah menjadi kerupuk wortel dan sirup wortel serta pendapatan yang dihasilkan dari usaha olahan kerupuk wortel dan sirup wortel di KWT Citeko Asri Desa Citeko Desa Citeko Kecamatan Cisarua Kabupaten Bogor. Penelitian ini bertujuan untuk menganalisis nilai tambah dan pendapatan wortel setelah diolah menjadi kerupuk wortel dan sirup wortel di KWT Citeko Asri Desa Citeko Kecamatan Cisarua Kabupaten Bogor.

\section{BAHAN DAN METODE}

\section{Lokasi dan Waktu}

Penelitian dilakukan di KWT Citeko

Asri Desa Citeko Kecamatan Cisarua Kabupaten Bogor Provinsi Jawa Barat. Penentuan lokasi ini secara sengaja dilakukan karena kecamatan ini berada di daerah dataran tinggi dan banyak petani yang bercocok tanam tanaman wortel sehingga wortel tersebut bisa dibuat menjadi beberapa jenis olahan. Kegiatan penelitian ini dilakukan selama 1 bulan, dimulai 10 September-10 Oktober 2014.

\section{Metode Penentuan Responden}

Penelitian yang dilakukan di KWT Citeko Asri mengenai produk olahan kerupuk wortel dan sirup wortel merupakan penelitian deskriptif dengan pendekatan kualitatif. Penentuan informan dalam penelitian ini menggunakan teknik purposive sampling atau sampling bertujuan untuk meningkatkan kegunaan informasi yang diperoleh dari sampel yang sedikit. Terdapat 3 informan dalam penelitian ini yaitu informan kunci (Ketua Gapoktan yang menaungin KWT Citeko Asri), informan utama (Ketua Kwt Citeko Asri) dan informan tambahan (Anggota KWT Citeko Asri).

\section{Metode Pengumpulan Data}

Jenis data yang digunakan dalam penelitian ini terdiri atas: data primer dan data sekunder Data primer adalah data yang langsung diperoleh melalui wawancara. Data sekunder adalah data yang diperoleh melalui kegiatan kepustakaan, internet, Dinas Tanaman Pangan, Badan Pusat Statistika (BPS) dan sumber lain yang terkait (Lumintang, 2013).

\section{Metode Analisis Data}

Pengolahan dan analisis yang digunakan dalam penelitian ini adalah analisis kuantitatif. Analisis kuantitatif dengan menggunakan metode hayami untuk menghitung nilai tambah olahan kerupuk wortel dan sirup wortel. Metode yang dilakukan dalam menentukan pendapatan usaha menggunakan analisis pendapatan usaha, BEP (Break Event Point) dan R/C Rasio. Data yang diperoleh dari penelitian ini kemudian ditabulasi terlebih dahulu dan diolah dengan menggunakan bantuan komputer dengan program Microsoft Office Excel 2013.

\section{HASIL DAN PEMBAHASAN}

\section{Analisis Nilai Tambah}

Rata-rata penggunaan bahan baku berupa wortel dalam proses pembuatan kerupuk wortel di KWT Citeko Asri adalah 
18 kilogram per proses produksi dan ratarata penggunaan bahan baku berupa wortel dalam pembuatan sirup wortel adalah $18 \mathrm{~kg}$. Pengolah wortel memperoleh bahan baku dari petani wortel di Desa Citeko Kec. Cisarua. Hasil produksi dari pengolahan rata-rata bahan baku per proses produksi adalah 9 kilogram produk berupa kerupuk wortel. Hasil produksi sirup wortel dari pengolahan rata-rata bahan baku per produksi adalah 9 liter.

Tenaga kerja adalah jumlah orang yang dibutuhkan dalam proses produksi. Ketersediaan tenaga kerja mutlak dibutuhkan dalam proses produksi. Rata-rata kebutuhan tenaga kerja dalam satu kali proses produksi kerupuk wortel adalah 5 HOK. Satu HOK adalah delapan jam atau enam jam kerja wanita. Besarnya nilai koefisien tenaga menunjukkan besarnya sumbangan tenaga kerja yang dibutuhkan untuk mengolah satu $\mathrm{kg}$ wortel menjadi kerupuk wortel, dan besarnya sumbangan tenaga kerja yang dibutuhkan untuk mengolah satu $\mathrm{kg}$ wortel menjadi sirup wortel.

Nilai faktor konversi untuk produk kerupuk wortel adalah jumlah output dibagi dengan input yang digunakan. Rata-rata nilai faktor konversi adalah sebesar 0,5. Nilai faktor konversi menunjukkan bahwa setiap 18 kilogram wortel mampu menghasilkan 9 kilogram kerupuk wortel. Nilai faktor konversi untuk sirup wortel adalah jumlah output dibagi dengan input yang digunakan. Rata-rata nilai faktor konversi untuk sirup wortel adalah sebesar 0,5. Nilai faktor konversi menunjukkan bahwa setiap $18 \mathrm{~kg}$ wortel mampu menghasilkan 9 liter sirup wortel.

Rata-rata nilai koefisien tenaga kerja sebesar 0,278 menunjukkan bahwa untuk mengolah 18 kilogram wortel menjadi kerupuk wortel diperlukan tenaga kerja langsung sebanyak 5 HOK. Dari nilai koefisien tenaga kerja dapat dilihat apakah pengusaha sudah efisien berproduksi atau belum. Semakin kecil nilai koefisien tenaga kerja maka semakin efisien pengusaha berproduksi. Rata-rata nilai koefisien tenaga kerja pada pengolahan sirup wortel adalah sebesar 0,056, hal ini berarti untuk mengolah $18 \mathrm{~kg}$ wortel menjadi 9 liter sirup wortel dibutuhkan $1 \mathrm{HOK}$. Rata-rata harga jual dari KWT Citeko Asri kerupuk wortel di pengecer adalah Rp 40.000 per kilogram sedangkan harga jual sirup wortel adalah $\mathrm{Rp}$ 15.000 per liter.

\section{Analisis Pendapatan Usaha Olahan Wortel Menjadi Kerupuk Wortel dan Sirup Wortel}

Penerimaan usaha olahan kerupuk wortel dan sirup wortel diperoleh dari hasil penjualan produk yang dihasilkan. Penerimaan dari kedua produk olahan kerupuk wortel dan sirup memberikan nilai sebesar Rp 9.900.000,- per bulan dan total biaya-biaya dalam satu bulannya, usaha ini membutuhkan biaya produksi untuk menghasilkan kerupuk wortel dan sirup wortel sebesar Rp 7.453.275,--. Sehingga dalam satu bulan produksi usaha yang dijalankan oleh KWT Citeko Asri berupa produk olahan kerupuk wortel dan sirup wortel menerima pendapatan usaha sebesar Rp 2.446.725,- per bulan. Hasil Perhitungan $\mathrm{R} / \mathrm{C}$ Rasio dari produk olahan kerupuk wortel dan sirup wortel yaitu sebesar 1,33. Artinya adalah dengan pengeluran $\mathrm{Rp}$ 1,maka akan menghasilkan penerimaan sebesar Rp 1,33,-, sehingga semakin besar keuntungan yang didapatkan maka akan semakin besar R/C yang di dapat pada suatu usaha. Usaha olahan kerupuk wortel dan sirup wortel yang dijalankan oleh KWT Citeko Asri yang berada di Desa Citeko memberikan keuntungan kerena usaha olahan kerupuk wortel dan sirup wortel memberikan nilai $\mathrm{R} / \mathrm{C}>1$.

Pemasaran produk olahan kerupuk wortel dan sirup wortel yang dilakukan oleh 
KWT Citeko Asri yaitu dengan cara menjual produk tersebut melalui warung yang berada di daerah disekitar Desa Citeko. Selain itu produk ini dijual jika ada pesanan dari konsumen yang berkunjung di Gapoktan Bunga Wortel atau berkunjung di KWT Citeko Asri. Ketika Dinas Pertanian maupun dari pemerintah mengadakan pameran produk olahan dan hasil pertanian maka KWT Citeko Asri ikut serta dalam kegiatan tersebut yang bertujuan untuk mempromosikan produk olahan berbahan wortel dan menjual produk olahan tersebut kepada konsumen.

\section{KESIMPULAN DAN IMPLIKASI KEBIJAKAN}

\section{Kesimpulan}

Hasil analisis nilai tambah menunjukkan besarnya nilai tambah kerupuk wortel yang diperoleh sebesar Rp. 14.000/kg dengan persentase sebesar $70 \%$ dan pada nilai tambah sirup wortel diperoleh sebesar Rp. 3.500/liter dengan persentase sebesar $46,67 \%$. Keuntungan dari olahan kerupuk wortel sebesar Rp 8.444/kg dengan persentase keuntungan sebesar 60,32\% sedangkan keuntungan olahan sirup wortel sebesar Rp 2.389/liter dengan persentase keuntungan sebesar 68,25\%. Hasil nilai tambah dari olahan diatas menunjukan bahwa nilai rasio bernilai tinggi karena memiliki persentase $>40 \%$.

Usaha olahan kerupuk wortel dan sirup wortel yang dijalankan KWT Citeko Asri menerima pendapatan sebesar Rp 2.446.725,- per bulan. Berdasarkan dari nilai BEP usaha produk kerupuk wortel yaitu sebanyak 136,6 $\mathrm{kg}$ atau sama dengan $\mathrm{Rp}$ 30.357,- per kg sedangkan pada BEP sirup wortel sebanyak 133,0 liter atau sama dengan Rp 11.085,- per liter. R/C dari produk olahan kerupuk wortel dan sirup wortel yaitu sebesar 1,33. Artinya dengan pengeluran Rp 1,- maka akan menghasilkan penerimaan sebesar $\mathrm{Rp} 1,33,-$, sehingga semakin besar $\mathrm{R} / \mathrm{C}$ rasio yang didapatkan maka akan semakin besar keuntungan yang diperoleh dari usaha tersebut.

\section{Implikasi Kebijakan}

Implikasi kebijakan yang dapat diambil adalah sebagai berikut :

1. KWT Citeko Asri diharapkan dapat mengembangkan produk olahannya menjadi produk olahan yang siap konsumsi oleh konsumen dan memperbaiki kemasan dari produk olahan tersebut serta untuk memperluas pemasaran dari produk olahan wortel dikarenakan Desa Citeko merupakan salah satu daerah wisata di Kecamatan Cisarua. Melakukan perizinan terhadap produk olahan tersebut kepada Depkes, LPPOM atau BPOM dalam kemasan produk olahan wortel.

2. Bahan baku wortel tersedia cukup banyak tetapi KWT Citeko Asri tidak dapat mengolah secara maksimal sehingga perlu adanya ketersediaan bantuan berupa alat-alat untuk mempercepat proses produksi dalam pembuatan produk olahan kerupuk wortel dan sirup wortel.

3. Usaha olahan wortel memiliki potensi untuk dikembangkan tetapi pengetahuan dan keterbatasan modal menjadi kendala dalam mengembangkan usaha ini. Oleh karena itu, perlunya perluasan informasi tentang produk olahan yang berbahan baku wortel dan bantuan permodalan dalam rangka meningkatkan kualitas hasil produk olahan wortel khususnya kerupuk wortel dpan sirup wortel.

\section{DAFTAR PUSTAKA}

Badan Pusat Statistika. 2013. Luas Panen dan Produksi Wortel Tahun 2009- 
2013. www.bps.go.id (10 September 2014).

Dinas Pertanian Tanaman Pangan Jabar. 2012. Penghasil Wortel Wilayah Jawa Barat 2008-2012. www.diperta.jabarprov.go.id September 2014).

Effendi I, Oktariza W. 2006. Manajemen Agribisnis Perikanan. Penebar Swadaya. Depok.

Hernanto, Fadholi. 1988. Ilmu Usaha Tani. Penebar Swadaya. Jakarta.

Kamisi LH. 2011. Analisis Usaha dan Nilai Tambah Agroindustri Kerupuk Singkong. [Skripsi] Fakultas Pertanian. Universitas Muhammadiyah Maluku Utara.Ternate.

Kasmir, Jakfar. 2004. Study Kelayakan Bisnis. Prenada Media. Jakarta.
Kusuma PTW, Mayasti NKI. 2014. Analisis Kelayakan Finansial Pengembangan Usaha Produksi Komoditas Lokal : Mie Berbasis Jagung. AGRITECH, Vol. 34, No. 2, Mei 2014. Balai Besar Pengembangan Teknologi Tepat Guna, Lembaga Ilmu Pengetahuan Indonesia. Subang. Jawa barat.

Hardjanto W. 1993. Bahan Kuliah Manajemen Agribisnis. Jurusan Ilmuilmu Sosial Ekonomi Pertanian. Fakultas Pertanian. IPB. Bogor.

Hayami Y, Kawagoe T, Morooka Y, Siregar M. 1987. Agricultural Marketing and Processing in Upland Java a Perspective from a Sunda Village. CGPRT Centre. Bogor. 